\title{
ERRATUM
}

\section{Insufficient evidence to support separate BMI definitions for obesity in children and adolescents from South Asian ethnic groups in the UK}

RM Viner, T Fry, S Gupta, S Kinra, D McCarthy, S Saxena, S Taylor, JCK Wells, P Whincup and MJS Zaman

International Journal of Obesity (2010) 34, 945; doi:10.1038/ijo.2010.8

Correction to: International Journal of Obesity (2010) 34, 656-658; doi:10.1038/ijo.2009.237; published online 22 December 2009

Since the publication of the above paper, the authors have noticed that one of the authors has been omitted:

Professor Tim J Cole

MRC Centre of Epidemiology for Child Health, UCL Institute of Child Health, University College London
The full list of authors is:

RM Viner, TJ Cole, T Fry, S Gupta, S Kinra, D McCarthy, S Saxena, S Taylor, JCK Wells, P Whincup and MJS Zaman

The typesetters apologize for the mistake. 